\title{
Physical fluxes in urban environment
}

\author{
Book or Report Section
}

Accepted Version

Lietzke, B., Vogt, R., Young, D. T. and Grimmond, C. S. B. (2014) Physical fluxes in urban environment. In: Chrysoulakis, N., de Castro, E. A. and Moors, E. J. (eds.) Understanding Urban Metabolism. Routledge, pp. 29-44. ISBN 9780415835114 Available at https://centaur.reading.ac.uk/52794/

It is advisable to refer to the publisher's version if you intend to cite from the work. See Guidance on citing.

Publisher: Routledge

All outputs in CentAUR are protected by Intellectual Property Rights law, including copyright law. Copyright and IPR is retained by the creators or other copyright holders. Terms and conditions for use of this material are defined in the End User Agreement.

\section{www.reading.ac.uk/centaur}

\section{CentAUR}

Central Archive at the University of Reading

Reading's research outputs online 


\title{
PHYSICAL FLUXES IN URBAN ENVIRONMENT
}

\author{
Björn Lietzke ${ }^{1}$, Roland Vogt ${ }^{1}$, Duick T. Young ${ }^{2}$, CSB Grimmond ${ }^{3}$
}

${ }^{1}$ University of Basel, MCR Lab at the Department of Environmental Sciences, Klingelbergstrasse 27, CH-4056, Basel, Switzerland, t. +41 61 2670 700, roland.vogt@ unibas.ch ${ }^{2}$ King 's College London, UK; Meteorology, University of Reading, UK ${ }^{3}$ Meteorology, University of Reading, Reading, United Kingdom; King's College London, UK

\section{URBAN METABOLISM: THE METEOROLOGICAL VIEW}

Meteorologists are most interested in understanding how energy in the form of radiation and heat influences the urban climate and how this energy is transported, transformed and stored (e.g. in urban building structures). They also are interested in the effects of precipitation on cities, how storm water runoff is changed and how much water is emitted into the atmosphere through evapotranspiration. In addition, they want to know how much cities worldwide contribute to climate change through their emissions to the global carbon cycle. For meteorologists to address the challenges of sustainable cities and urban planning, information on the distribution and flows of energy, water and carbon in typical urban systems have to be known.

From a meteorological perspective, the urban metabolism of a city is strongly dependent on the prevailing regional and local climate and its built-up structure. Together these define the microclimate within the street canyons, on the roads, in the buildings, and at any other place in an urban area. In this context, the urban energy, water and carbon balances are presented in this Chapter.

\section{URBAN ATMOSPHERE}

\section{Layers and Scales}

A key issue of importance for urban investigations is the definition of the appropriate scale of a study area. A classification of urban canopy layer (UCL) elements according to scale considerations is given in Table 4.1. Vertically, the urban atmosphere can be divided into layers as illustrated in Figure 4.1. The lower atmosphere that is influenced by the urban structure is called the urban boundary layer (UBL). From the ground up to roughly the average height of roughness elements like buildings or trees $\left(z_{h}\right)$ is the UCL. It is produced by micro-scale processes in their immediate surroundings. The UCL is part of the roughness sublayer (RSL) which is dependent on the height and density of roughness elements and extends to the height $z_{*}=a \cdot z_{h}$ where $a$ ranges between 2 and 5 (Raupach et al. 1991). Above this is the inertial sublayer (ISL) where under ideal conditions vertical fluxes of energy or matter can be expected to be constant with height. The upper part of the UBL, which is to a large extent determined by meso-scale advective processes, is referred to as the outer urban boundary layer (Rotach et al. 2005).

Table 4.1: Classification of elements of the urban canopy layer (UCL) and their scales (adapted from (Oke 2006).

\begin{tabular}{|c|c|c|c|}
\hline UCL units & Built features & $\begin{array}{l}\text { Meteorological } \\
\text { scale }\end{array}$ & $\begin{array}{l}\text { Typical horizontal length } \\
\text { scales }\end{array}$ \\
\hline 1. Element & Individual surface element (pavement, trees etc.) & Micro & $<10 \mathrm{~m} \times 10 \mathrm{~m}$ \\
\hline 2. Building & Building & Micro & $10 \mathrm{~m} \times 10 \mathrm{~m}$ \\
\hline 3. Canyon & Street, canyon, property & Micro & $30 \mathrm{~m} \times 40 \mathrm{~m}$ \\
\hline 4. Block & Block, neighbourhood, factory & Micro/Local & $0.5 \mathrm{~km} \times 0.5 \mathrm{~km}$ \\
\hline 5. Land-use class (UTZ, UCZ, LCZ, UZE) ${ }^{*}$ & City center, residential, or industrial zone & Local & $5 \mathrm{~km} \times 5 \mathrm{~km}$ \\
\hline 6. City & Urban area & Local/Meso & $25 \mathrm{~km} \times 25 \mathrm{~km}$ \\
\hline 7. Urban region & City plus its environs & Meso & $100 \mathrm{~km} \times 100 \mathrm{~km}$ \\
\hline
\end{tabular}

* A number of different classifications at this scale exist including: Urban Terrain Zones (Ellefsen 1990/91), Urban Climate Zones (Oke 2006), Local Climate Zone (Stewart \& Oke 2012), Urban Zones for Energy partitioning (Loridan \& Grimmond 2012).

\section{Processes and Variability}

The exchange of mass and scalars in the urban atmosphere is governed by several processes linked to the heterogeneity of the 3D urban structure. These have a direct influence on the emission and distribution of energy, water and carbon and their transport to the atmosphere. Enhanced mechanical and thermal turbulence in cities change the wind field and induce perturbed streamlines which have an influence on micro to local-scale transport processes.
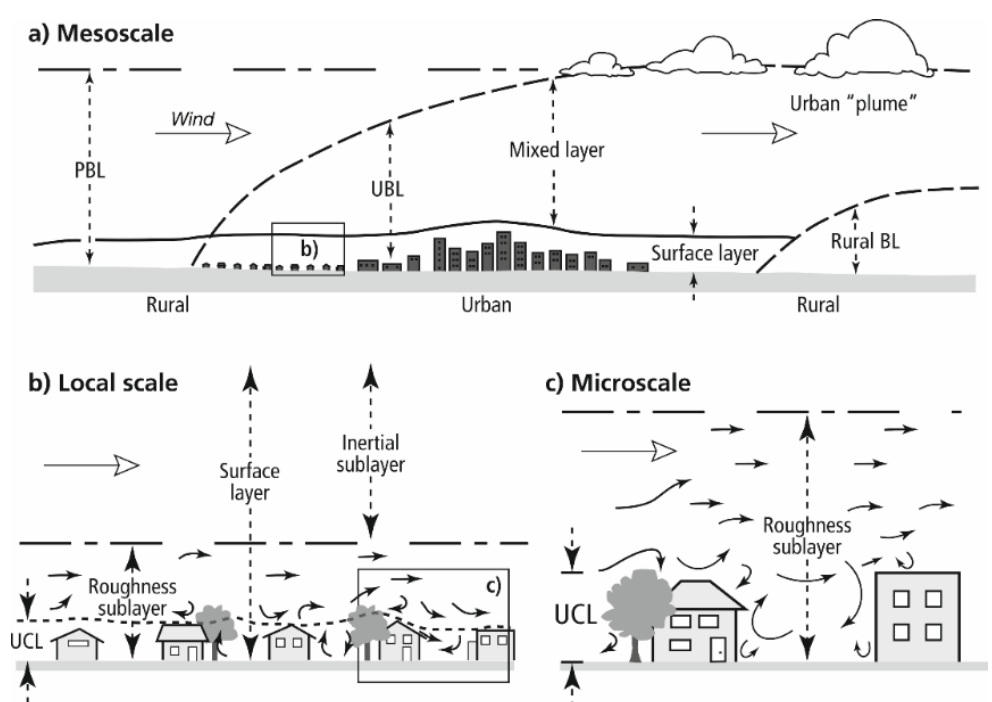

Given urban areas are not spatially homogeneous, atmospheric measurements in the UBL are strongly dependent on the spatial and temporal source/sink distribution. This leads to strict requirements for the siting of measurement instruments (Feigenwinter et al. 2012, Oke 2006) as vertical turbulent fluxes, for example, are extremely sensitive to strong local sources in combination with prevailing wind directions (Lietzke \& Vogt 2013). Ideal sites are hard to find and it is thus of great importance to know the source area of atmospheric measurements, i.e. the urban area for which observations are representative of.

Figure 4.1: Scales and Layers (planetary boundary layer PBL, urban boundary layer $U B L$, urban canopy layer $U C L)$ in the urban atmosphere (Feigenwinter et al. 2012, adapted from Oke 2006). 


\section{METHODS}

The energy, water and carbon balances of an urban system can be determined by considering their physical flows in and out of a control volume, which, considering mass conservation, leads to a volume balance approach as depicted in Figure 4.2.

The measurement of the fluxes is achieved with different, often very specific methods. These methods are discussed in the subsequent sections together with the respective processes they measure. One elementary and widely used method to derive the vertical exchange of energy and mass as part of an air volume, the Eddy Covariance (EC) method, is presented here, since this method was mainly used in the BRIDGE project (Chrysoulakis et al. 2013), as described in Chapter 5.

a)
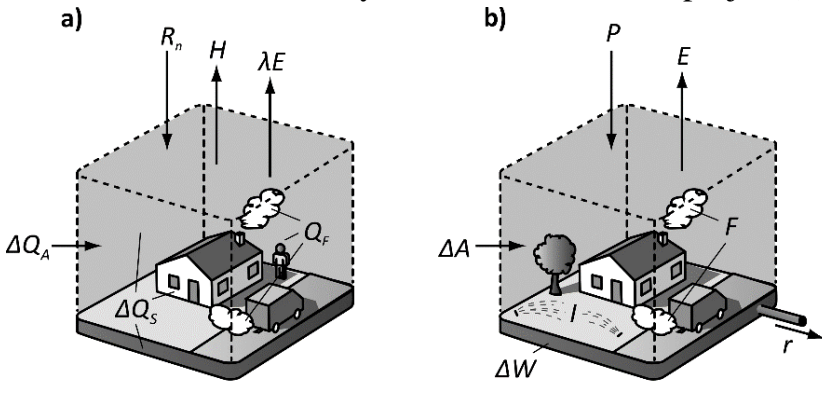

$P+I+F=E+r+\Delta W+\Delta A$

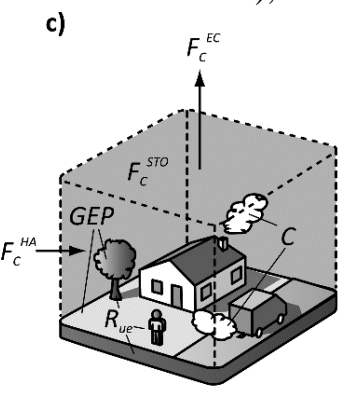

$F_{C}^{E C}+F_{C}^{S T O}=C+R_{u Q}-G E P+F_{C}^{H A}$

Figure 4.2: Schematic depiction of the (a) Urban Energy Balance; (b) Urban Water Balance; and (c) Urban Carbon Balance from a micrometeorological perspective. The directions of the arrows represent positive fluxes. Adapted from (Feigenwinter et al. 2012).

The EC method relies on the fact that atmospheric turbulence is usually the main vertical transport mechanism in the ISL of the UBL. High frequency variations (typically $10-20 \mathrm{~Hz}$ ) of the vertical wind component $w$ and the scalar $s$ of interest (e.g. $\mathrm{H}_{2} \mathrm{O}$ or $\mathrm{CO}_{2}$ ) are measured and, after decomposing into mean and turbulent parts by applying Reynolds averaging, their covariance $\overline{w^{\prime} s^{\prime}}$ gives the vertical turbulent exchange rate of the respective scalar. The primes denote the deviations from the mean and the overbar the average.

Measurements have to be situated at the top of the control volume (Figure 4.2), which is ideally inside the ISL, to capture the vertical transport in and out of the volume. The instrument of choice is usually an ultrasonic-anemometer-thermometer in combination with a gas-analyzer that measures the scalars of interest (see Chapter 5 for details). An extensive overview on the EC method is given in Aubinet et al. (2012).

For inhomogeneous urban areas, the EC method is more suitable than other approaches, such as the flux-gradient relations, which normally fail in the RSL (Christen 2005, Piringer et al. 2002, Roth \& Oke 1995). Measurements higher up in the ISL are difficult in urban areas due to a lack of higher towers and because of fetch considerations. Therefore, care needs to be taken when using micrometeorological techniques to consider averaging time, the flux source area and sensor placement to ensure representativeness of the flux in an urban context (Foken 2008, Grimmond 2006, Schmid \& Rotach 1997).

\section{PHYSICAL FLUXES}

\section{Energy fluxes - Urban Energy Balance Introduction}

Following the volume balance approach, the energy balance of an urban system (Urban Energy Balance - UEB) can be determined by considering the energy flows in and out of the control volume:

$$
R_{n}+Q_{F}=H+\lambda E+\Delta Q_{S}+\Delta Q_{A}
$$

where $R_{n}$ is the net all wave radiation, $Q_{F}$ is the anthropogenic heat flux, $H$ is the turbulent sensible heat flux, $\lambda E$ is the turbulent latent heat flux, $\Delta Q_{S}$ is the net storage change within the control volume and $\Delta Q_{A}$ is the net advected flux. All terms are usually expressed as energy flux density per horizontal, or vertical area (typically $\mathrm{W} \mathrm{m}^{-2}$, also $\mathrm{MJ} \mathrm{m}^{-2} \mathrm{~d}^{-1}$ for temporal sums). In the following sections each of the UEB terms are discussed.

Theoretical knowledge of the processes forming the UEB and the resultant effects on the urban boundary layer is well developed based on numerous observational studies. For typical urban areas, the daytime energy balance is characterized by a significant storage heat flux term, a strong sensible heat flux away from the surface and weak evapotranspiration. As a consequence of strong nocturnal release of stored heat, both turbulent heat fluxes remain directed upward on average at night, a notable difference to the rural environment. This has consequences for the stability of the urban ISL and the RSL which are thermally unstable most of the time (Christen 2005).

\section{Net all wave radiation $R_{n}$}

Net all wave radiation $\left(R_{n}\right)$ is the balance between the incoming $(\downarrow)$ and outgoing $(\uparrow)$ short- $(S W)$ and long-wave (LW) radiation fluxes and represents the primary source of energy in the UEB:

$$
R_{n}=S W \downarrow-S W \uparrow+L W \downarrow-L W \uparrow
$$

Measurements can be made using pyranometers for the shortwave fluxes and pyrgeometers for the long-wave fluxes, or by using net radiometers. In a typical urban atmosphere radiative fluxes are, if compared to their rural counterparts, altered by pollutants. Whereas SW $\downarrow$ will be reduced, $\mathrm{LW} \downarrow$ is greater. In typical mid-latitude cities, these changes are normally opposed by a lower shortwave albedo due to darker surface materials (whereas in low-latitude cities, walls and roofs are generally brighter) and a higher surface temperature at night, which augments the long-wave emission (Oke 1987). The net effect on urban/rural radiation differences therefore remains small (Oke 1987, Rotach et al. 2005).

\section{Anthropogenic heat flux $Q_{F}$}

The anthropogenic heat flux $\left(Q_{F}\right)$ derives mainly of combustion exhausts by stationary and mobile sources (Grimmond 1992, Sailor 2010). Thus, its contribution to the UEB tends to be highest in cold climates in the wintertime when the energy input from 
human sources is comparatively large (primarily due to domestic heating). But even in summertime it may become significant for cities with high air conditioning usage. $Q_{F}$ is difficult to determine because of its strongly varying patterns in space and time and because it cannot be measured directly. It is therefore not surprising that many different approaches to estimate this term can be found in literature.

A common approach is to estimate $Q_{F}$ based on inventories of existing socio-economic data, e.g. from energy use data (Sailor 2010). These kinds of data have been analysed as part of the BRIDGE project (Allen et al. 2010, Iamarino et al. 2012, Lindberg et al. 2013, Chapter 5). A second approach, if daily or yearly totals of the energy balance equation are considered, and $\Delta Q_{S}$ can be assumed to be zero, allows calculation of $Q_{F}$ as the residual term (Christen \& Vogt 2004, Pigeon et al. 2007a), or with storage heat flux measurements at a monthly diurnal time-scale (Offerle et al. 2005). A third approach explored as part of the BRIDGE project, uses micro-scale analysis of the eddy covariance data (Kotthaus \& Grimmond 2012) to determine the amount of energy released from buildings. This uses the 'spikes' of heat, water, and $\mathrm{CO}_{2} 10 \mathrm{~Hz}$ data, which impact the departure of the mean used in the eddy covariance calculation.

The spatial and temporal patterns of $Q_{F}$, have large impacts on the urban climate and is impacted by many of the urban planning alternatives (Chapter 3), therefore understanding the role and size of this term is important.

\section{Turbulent sensible heat flux $\mathrm{H}$}

The vertical transport of energy by the sensible heat flux $(H)$ as measured by the EC method is expressed:

$$
H=\rho c_{p} \overline{w^{\prime} T^{\prime}}
$$

where $\rho$ is the air density $\left(\mathrm{kg} \mathrm{m}^{-3}\right) c_{p}$ is the specific heat capacity of air $\left(\mathrm{J} \mathrm{kg}^{-1} \mathrm{~K}^{-1}\right)$ and $\overline{w^{\prime} T^{\prime}}$ is the average of the product of the turbulent fluctuations of air temperature $T$ and the vertical wind speed $w\left(\mathrm{~K} \mathrm{~m} \mathrm{~s}^{-1}\right)$. During daytime this term is primarily driven through energy input by $R_{n}$, while at night storage release from the urban structure keeps $H$ at a higher level compared to rural areas.

\section{Turbulent latent heat flux $\lambda E$}

The turbulent latent heat flux $\lambda \mathrm{E}$ transports moisture away from the surface because of a change of state (e.g. condensation, evaporation). This depends primarily on the availability of water, particularly the presence of vegetated areas (transpiration) or wet surfaces (evaporation). Similar to the sensible heat flux it can be written as:

$$
\lambda E=L_{v} \overline{w^{\prime} \rho_{v}^{\prime}}
$$

with $L v$ the latent heat of vaporization $\left(\mathrm{J} \mathrm{kg}^{-1}\right)$ and $\rho^{\prime}{ }_{v}$ the fluctuating water vapor density $\left(\mathrm{kg} \mathrm{m}^{-3}\right) . \lambda \mathrm{E}$ can be measured directly using the EC method (e.g. a sonic anemometer coupled with an open-path infrared gas analyzer). The quantification of $\lambda E$ is complicated by the extremely heterogeneous sources of moisture. This term is discussed further in the next Section, when evapotranspiration (its water equivalent) is considered.

\section{Net storage change $\Delta Q_{S}$}

The rate of change of heat storage $\left(\Delta Q_{S}\right)$ consists of the uptake or release of energy by the ground, buildings and vegetation and in the volume. It includes the changes of latent and sensible heat content in the air of the considered control volume. The latter changes are often neglected as they are small compared to the heat storage changes in urban materials.

$\Delta Q_{S}$ within an urban control volume can be theoretically expressed as the sum of storage fluxes for single surface elements (Offerle et al. 2005):

$$
\Delta Q_{S}=\sum_{i} \frac{\Delta T_{i}}{\Delta t}(\rho C)_{i} \Delta x_{i} \lambda_{p i}
$$

where $\Delta T / \Delta t$ is the rate of temperature change, $\rho C\left(\mathrm{~J} \mathrm{~m}^{-3} \mathrm{~K}^{-1}\right)$ is the volumetric heat capacity, $\Delta x(\mathrm{~m})$ is the element thickness and $\lambda_{p}\left(\mathrm{~m}^{2}\right)$ is the plan area index for each element $i$ (Offerle et al. 2005).

As cities are not expected to cool down, or heat up during a year, the annual total of $\Delta Q_{S}$ has to be zero by definition (Christen 2005, Offerle et al. 2005). This is helpful in calculating annual surface energy balances and in assigning annual residuals to other terms as, for example, the anthropogenic heat flux. $\Delta Q_{S}$ is a spatially and temporally variable term of the energy balance, depending on differences in surface type and radiant loading. It is of particular relevance in the urban energy balance as it can account for more than half of the daytime net radiation at highly urbanized sites (Roberts et al. 2006).

Direct measurements in urban areas are practically unattainable due to the complexity of urban structures and materials. $\Delta Q_{S}$ therefore has to be determined by indirect methods or models. As for most fluxes that are not directly measureable, there is a lack of standard for the determination of urban heat storage and quite a range of methods exist. A commonly used method is to consider the storage flux term as the residual of the energy balance (e.g. Christen \& Vogt 2004, Grimmond \& Oke 1995, Grimmond \& Oke 1999, Roth \& Oke 1994, Spronken-Smith et al. 2006):

$$
\Delta Q_{S}=R_{n}-H-\lambda E
$$

$\Delta Q_{A}$ and $Q_{F}$ are here considered as negligible. Another widely used parameterization approach is based on relations between the net-all wave radiation $R_{n}$ and the storage heat flux $\Delta Q_{S}$ for typical surface materials (Camuffo \& Bernardi 1982, Grimmond \& Oke 1991, Oke et al. 1981).

\section{Net advected flux $\Delta Q_{A}$}

Storage change in a control volume due to advection can be expressed as a result of the flow in and out of the volume as:

$$
\Delta Q_{A}=Q_{A}^{\text {in }}-Q_{A}^{\text {out }}
$$


The scale of the advection is critical relative to the scale of interest. Local-scale advection has largely been neglected for a long time in urban measurement studies based on assuming that the fetch conditions were similar so the term could be considered to be small and the theoretical assumption of horizontal homogeneity was adopted. However, the fetch is rarely sufficiently extensive and consistent, so the latter is often questionable.

To date $\Delta \mathrm{Q}_{\mathrm{A}}$ has only been investigated at the local-scale in urban environments in cities with meso-scale circulations, such as diurnal sea-breeze circulations (e.g. Pigeon et al. 2007b), or drainage flows (e.g. Spronken-Smith et al. 2006) where it has been shown to be important. The circulations between the city and the surroundings (e.g. Lemonsu et al. 2001) and because of localscale features (e.g. urban parks, Spronken-Smith et al. 2000) are thought to be important influences in urban areas. However, these processes remain under-studied in urban areas because of the vast array of instrumentation needed and the need to couple the observations with 3D modelling (e.g. Pigeon et al. 2007b). In the BRIDGE, the role of advection has been considered at the localscale in London (Kotthaus \& Grimmond 2013a and 2013b, Loridan et al. 2013).

\section{Water Fluxes - Urban Water Balance \\ Introduction}

The urban environment is significantly different to natural hydrological watersheds in terms of land use, water flows and surface cover leading to the modification of the hydrological cycle. In addition, the transport and removal of water through the piped water system adds an anthropogenic component. Artificial surfaces found in urban areas enhance the surface runoff leading to an enhanced risk of flooding and the transport of pollutants (Burian et al. 2002), along with a reduction in infiltration leading to lower replenishment of groundwater (Stephenson 1994).

The Urban Water Balance (UWB) applies the principle of mass conservation to the transfer of water through a specific domain, or catchment (Grimmond et al. 1986), allowing the study of both spatial and temporal patterns of water supply and usage (Mitchell et al. 2001). It can be written as (Grimmond \& Oke 1991):

$$
P+I+F=E+r+\Delta W+\Delta A
$$

where $P$ is precipitation, $I$ is the urban piped water supply, $F$ is water release due to human activity, $E$ is evapotranspiration, $r$ is runoff, $\Delta W$ is net change in water storage and $\Delta A$ is the net advection of moisture in and out of the control volume. Each of the terms is usually expressed as a depth of water, or as a volume per unit time. It is also common to express individual terms as a percentage of the annual precipitation (often assumed to be the main input into the system) especially in the study of individual components such as runoff and evapotranspiration (e.g. Berthier et al. 2006, Xiao et al. 2007).

\section{Precipitation $P$}

Precipitation is a key input into the UWB as the amount and intensity directly impact the potential magnitude of evapotranspiration, runoff and infiltration and the amount of recharge to surface and groundwater stores. The components of total precipitation $(P)$ are:

$$
P=P_{r}+P_{h}+P_{s}+P_{m}
$$

where $P_{r}$ is rainfall, $P_{h}$ is hail, $P_{s}$ is snow and $P_{m}$ is atmospheric moisture which condenses on contact with the surface in the form of fog, mist or dew. The form of precipitation dictates the timing of the availability of water for runoff, infiltration and evapotranspiration. Snow and hail, which fall in a solid/ semi-solid state, have to undergo a change of state to liquid or gaseous form and thus for a time period may be recorded as an increase in storage in the UWB. Depending on the climate, this can last for many months and affect the UWB at a later date through runoff or evaporation (e.g. Järvi et al. 2014, for Helsinki).

Precipitation measurement within urban areas has traditionally used tipping bucket raingauges. Radar can provide spatial information, but cannot be used alone due to uncertainty in its accuracy (Berne et al. 2004, Vieux \& Bedient 2004).

\section{Piped Water Supply I}

The total piped water supply $(I)$ consists of:

$$
I=I_{U}+I_{R}+I_{G}+I_{S}
$$

where $I_{U}$ is the internal residential/commercial/industrial water use, $I_{R}$ is water used for irrigation, $I_{G}$ is grey or other reused water and $I_{S}$ is the leakage to/from the piped network.

The magnitude of the water supplied is driven by a combination of demand from urban inhabitants and supply by the water utility companies or agencies, which is determined by availability of surface and groundwater supplies. Measurement of the supplied water is often from water utility company water meters (e.g. Morris et al. 2007).

Irrigation is a major component of piped water use in urban areas, where seasonal precipitation and weather patterns are particularly variable (Mitchell et al. 2001), with variability in irrigation related to specific weather events (Grimmond \& Oke 1986). However, determining the actual amount of irrigation (as with other water usage) is a much more complex problem as it is related to the human perception and behaviour (e.g. Arnfield 2003, Grimmond \& Oke 1986).

\section{Anthropogenic Water Release due to Combustion F}

Anthropogenic water release due to combustion of fuels and from industry consists of:

$$
F=F_{M}+F_{I}+F_{V}+F_{W}
$$

where $F_{M}$ is the release of moisture from air conditioning, heating and cooling applications, $F_{I}$ is the moisture released from industry, $F_{V}$ is the moisture released due to combustion of from vehicles and $F_{W}$ is consumption of bottled water. This term has not been neither widely investigated, nor often considered in UWB models (e.g. Grimmond et al. 1986, Mitchell et al. 2001), but 
in large cities this term can become more important (Moriwaki \& Kanda 2004). In Tokyo, Japan local-scale EC observations over a heavily urbanised area (very little vegetation) displayed significantly large latent heat fluxes ( $>100 \mathrm{~W} \mathrm{~m}^{-2}$ and at times greater than observed sensible heat flux) in the summer months, as a result of anthropogenic moisture release from building cooling systems (Moriwaki et al.2008).

\section{Evapotranspiration $\boldsymbol{E}$}

Evapotranspiration includes evaporation of surface water and transpiration through vegetation of water from the sub-surface vadose zone (Xiao et al. 2007). The term is used interchangeably with evaporation in many studies where it is impractical to separate the two components (Brutsaert 1982):

$$
E=E_{V}+E_{T}
$$

where $E_{V}$ is evaporation and $E_{T}$ is transpiration. Its energy equivalent is the latent heat flux $Q_{E}$.

Given that water is typically limited at the surface within cities due to high areal fractions of un-vegetated and impervious surfaces, actual evaporation rates are limited by surface controls and energy availability. When water availability is unlimited the theoretical maximum evaporation is typically referred to as potential evaporation which is usually greater than the actual evaporation (Aston 1977). Despite these limiting factors, E can be one of the most important terms in the UWB as a result of complex microclimates, surface storage and irrigation (Berthier et al. 2006, Grimmond \& Oke 1986, Grimmond \& Oke 1991, Grimmond \& Oke 1999, Mitchell et al. 2001).

Urban parks and open water bodies are of particular interest due to the relatively high vegetation cover and greater amount of available moisture resulting in distinct microclimates (the former akin to that of a desert oasis) in comparison to surrounding more built up areas (Hathway \& Sharples 2012, Spronken-Smith et al. 2000, Steeneveld et al. 2014). Spronken-Smith et al. 2000 observed that daily total evapotranspiration in a park in Sacramento, USA was greater than $300 \%$ of the total from the surrounding irrigated suburban area.

Observation of evapotranspiration has been undertaken using mini-lysimeters at the micro-scale (Oke 1979), while at the localscale, micrometeorological techniques are often applied (e.g. EC). Alternatively when direct measurement is unavailable it can be determined as a residual term of the UWB equation or using the Bowen ratio energy balance (Nouri et al. 2012). Goldbach \& Kuttler 2013 found in Oberhausen, Germany, using EC, that absolute daily maximum evapotranspiration varied by up to $90 \%$ between urban and suburban areas where vegetated surface fractions were 0.18 and 0.58 , respectively. Datasets from 19 EC sites located in urban and suburban areas of 15 cities worldwide indicated a positive relation between the active vegetated index (indices based on vegetated fraction and seasonal leaf-area index (Loridan et al. 2011)) and mean midday evapotranspiration, with a stronger linear dependence on observed E rates prevalent when active vegetated index was $<0.43$ (Loridan \& Grimmond 2012).

\section{Runoff $r$}

Runoff is the flow over the surface and through drainage pipes. It represents water that has not been captured by some intermediate store (e.g. tree canopy, roof or surface storage) or has not infiltrated into sub-surface stores within a particular time period. A greater fraction of impervious surfaces in cities in comparison to rural areas leads to more rapid surface flows often enhanced by drainage networks (Semadeni-Davies \& Bengtsson 1999). The increase in runoff can lead to a higher probability of flooding and the transport of pollutants (Burian et al. 2002, Xiao et al. 2007). Urban runoff consists of:

$$
r=r_{S}+r_{W}+r_{O}+r_{L}+r_{F}
$$

where $r_{S}$ is storm water runoff (through storm drains), $r_{W}$ is waste water flow (sewer system), $r_{O}$ is runoff released by snow melt, $r_{L}$ is surface runoff (e.g. overland flow and roof runoff) and $r_{F}$ is surface infiltration. The rate and magnitude of runoff are regulated by the rate of precipitation, soil moisture content (influences infiltration), land surface properties (e.g. fraction of vegetation cover and permeability), local topography and the design of the drainage system infrastructure.

Runoff is often either modelled in the UWB due to a lack of measured data or the size of the study catchment (Branger et al. 2013, Wang et al. 2008), parameterized using infiltration/runoff coefficients (Hollis \& Ovenden 1988) or as a residual (Jia et al. 2001). However runoff measurement is possible directly using flow meters to determine discharge through a drainage system (Ragab et al. 2003b), or controlled study area (Stephenson 1994, Xiao et al. 2007), water capture to collect and measure roof runoff (Hollis \& Ovenden 1988, Ragab et al. 2003a), or indirectly using water balance techniques to determine available water for potential runoff (Inkiläinen et al. 2013). In the BRIDGE case studies, the runoff in two small catchments were observed in Helsinki (see Chapter 10 for details).

\section{Net Storage Change $\Delta W$}

The net change in storage term $(\Delta W)$ refers to the change in water storage within the study catchment. Its magnitude is determined by

$$
\Delta W=\Delta W_{g}+\Delta W_{m}+\Delta W_{W}+\Delta W_{a}+\Delta W_{n}
$$

where $\Delta W_{g}$ is the net change in ground water storage, $\Delta W_{m}$ is the net change in soil moisture storage, $\Delta W_{W}$ is surface water storage (e.g. ponds and lakes), $\Delta W_{a}$ is anthropogenic storage (e.g. storm water holding and water butts) and $\Delta W_{n}$ is the net change in snowpack storage.

For large catchments groundwater within the soil and deeper aquifer(s) can be significant. Techniques to measure soil moisture include tensionmeters (Berthier et al. 2004), gravimetric sampling (Grimmond \& Oke 1986), time domain reflectometry and groundwater levels can be observed through boreholes (Stephenson 1994). 


\section{Net Moisture Advection $\Delta A$}

The net moisture advection is the horizontal transport of moisture by atmospheric flow. It is driven by flows at a number of atmospheric scales ranging from micro and local-scale turbulence to meso-scale circulations (e.g. sea breezes and valley flow). In many UWB studies the net moisture advection is not considered (e.g. Grimmond et al. 1986, Lemonsu et al. 2007).

\section{Carbon fluxes - Urban Carbon Balance Introduction}

Compared to energy and water, the urban balance of carbon - in the form of $\mathrm{CO}_{2}$ - shows greater deviations from its rural counterpart. Anthropogenic $\mathrm{CO}_{2}$ emissions, derived from the burning of fossil fuels are the major net source for global atmospheric carbon (Denman et al. 2007) and cities contribute a great share. Thus, knowledge of the spatiotemporal distribution of sources and sinks in urban environments and the processes that determine atmospheric transport in the UBL is of great importance.

Using a volume budget approach that focuses on surface-atmosphere processes, the Urban Carbon Balance (UCB) can be written as:

$$
F_{C}^{E C}+F_{C}^{S T O}=C+R_{u e}-G E P+F_{C}^{H A}
$$

where $F_{C}^{E C}$ is the integrative turbulent mass flux density of $\mathrm{CO}_{2}, F_{C}^{S T O}$ is the storage change between the surface and the measurement level, $C$ represents emissions through anthropogenic combustion processes, $R_{u e}$ is the respiration of the urban ecosystem (including from humans), GEP stands for the sink effects due to photosynthesis and $F_{C}^{H A}$ is the horizontal advection contribution. Terms are usually expressed as $\mathrm{CO}_{2}$ flux density per horizontal or vertical area (typically $\mu \mathrm{mol} \mathrm{m}^{-2} \mathrm{~s}^{-1}$ or kg m $\mathrm{m}^{-2} \mathrm{a}^{-1}$.)

\section{Turbulent carbon dioxide flux $F_{C}^{E C}$}

A common way to determine the turbulent vertical mass flux density of $\mathrm{CO}_{2}\left(F_{C}^{E C}\right)$ is by the use of the EC method, combining sonic with infrared gas analyzer measurements (a list of urban studies can be found in (Lietzke et al. 2014, in review). Two types of gas analyzers are widely used: open path analyzers where $\mathrm{CO}_{2}$ concentrations are measured instantaneously in the probed air volume (e.g. Moriwaki \& Kanda 2004, Vogt et al. 2006) and closed path analyzers where air is sucked through a tube into an enclosed measurement system (e.g. Grimmond et al. 2002, Järvi et al. 2012). The first has the advantage of measuring in situ but is sensitive to disturbances of the measurement path, e.g. through rain, dew or dust. The latter measurements are subject to a time lag and an attenuation of the signal, dependent on the length of the tube, but are not influenced by meteorological disturbances (Grimmond et al. 2002, Järvi et al. 2009).

Summing $F_{C}^{E C}$ over a defined timescale yields the net urban ecosystem exchange $(N u E E)$ rate analogous to the net ecosystem exchange (NEE) rates of rural ecosystems. The main contrast to non-urban ecosystems is that the urban surfaces generally act as a $\mathrm{CO}_{2}$ source; consequently $F_{C}^{E C}$ is nearly always positive. This results in positive $N u E E$ values which are usually higher the more urbanized an area is.

\section{Net storage change in the air $F_{C}^{S T O}$}

Fluxes in the RSL are not constant with height (Rotach 2001) and thus a vertical flux divergence over time has to be assumed in the air volume between the urban surface and the measurement level. This is considered in the term $F_{C}^{S T O}$, which can be determined using representative measurements of the concentration change within the air volume over time (Feigenwinter et al. 2012). In an urban environment, this would need several vertical profile measurements to account for the spatial variability within the EC source area - which is rarely feasible. Similar to $\Delta Q_{S}, F_{C}^{S T O}$ can assumed to be zero over a longer time period. On a diurnal scale it becomes relevant as, for example, nocturnally accumulated $\mathrm{CO}_{2}$ in the shallow UBL and the street canyons is flushed in the morning, when thermal mixing starts, leading to an overestimation of $F_{C}^{E C}$ compared to the actual emissions (Feigenwinter $e t$ al. 2012).

\section{Combustion C}

Anthropogenic emissions through combustion of fossil fuels are the main contributors to the UCB, consisting of:

$$
C=C_{B}+C_{V}
$$

The combustion from buildings $\left(C_{B}\right)$ and vehicular traffic $\left(C_{V}\right)$ can be distinguished by the type of fuel they burn (natural gas, oil or wood for heating versus gasoline or diesel for driving) and the spatio-temporal emission patterns. Source distribution is, as for $Q_{F}$, very heterogeneous. While $C_{V}$ can be considered as a line source on the bottom of the control volume that is primarily dependent on the diurnal/weekly traffic use behavior, $C_{B}$ generated by heating depends on climate related human activity (heating in winter, air conditioning in summer), has a distinct seasonal cycle (Lietzke et al. 2014, in review) and consists of point sources at certain heights (e.g. chimneys) (Kotthaus \& Grimmond 2012). Industry emissions as a part of $C_{B}$ follow their own patterns that need to be taken into account as appropriate.

Through isotopic analyses of air samples (Clark-Thorne \& Yapp 2003, Pataki et al. 2003), the fraction of atmospheric $\mathrm{CO}_{2}$ generated by either $C_{B}$ or $C_{V}$ can be derived. Inventory based approaches using fossil fuel consumption data and traffic density analyses (e.g. Helfter et al. 2011, Ward et al. 2013) can give an estimate on $C_{B}$ and $C_{V}$, or are used as input to model their contributions. Spatiotemporal adequately resolved data is rarely available so that e.g. fuel consumption often has to be scaled down from city to neighbourhood or building-scale (e.g. Christen et al. 2011). An indicator of fuel burned for heating purposes can be heating degree days based on outside air temperature and the desired inside air temperature (Lietzke et al. 2014, in review). 
Urban ecosystem respiration $\left(R_{u e}\right)$ can be separated into respiration of soils and vegetation $\left(R_{S V}\right)$, waste decomposition $\left(R_{W}\right)$ and human respiration $\left(R_{M}\right)$ :

$$
R_{u e}=R_{S V}+R_{W}+R_{M}
$$

Compared to natural ecosystems, urban $R_{S V}$ is influenced by irrigation and fertilization. $R_{M}$ depends on the density of people that live or work in an area and, on the basis of an individual, the physiological level of activity (active, resting, sleeping etc.). Moriwaki \& Kanda 2004 estimated human body respiration emissions at rest to be $8.87 \mathrm{mg} \mathrm{CO}_{2} \mathrm{~s}^{-1}$.

\section{Gross ecosystem productivity GEP}

Gross ecosystem productivity $(G E P)$ is a measure of the uptake of $\mathrm{CO}_{2}$ through photosynthesis from the air. In cities, both $G E P$ and $R_{S V}$ are primarily dependent on the surface fraction of vegetation (parks, lawns and trees), its density and type and the local climate which determines the seasonal photosynthesis rate. Productivity of urban vegetation is usually high due to irrigation, higher temperatures, less frost damage (urban heat island) and fertilization (e.g. NOX deposition) (Trusilova \& Churkina 2008), but physiological stress due to air pollution may lead to reduced GEP. Chamber measurements (Christen et al. 2011) help in estimating soil and lawn activity. In urban areas, photosynthesis is typically not able to compensate for the high $\mathrm{CO}_{2}$ emissions by combustion (Kotthaus \& Grimmond 2012, Lietzke \& Vogt 2013), but may have a limiting effect on measured fluxes (Coutts et al. 2007, Kordowski \& Kuttler 2010, Ward et al. 2013). Depending on the extent of urbanization, particularly vegetation effects, temporary sink effects can be observed (e.g. Crawford et al. 2011, Ramamurthy \& Pardyjak 2011).

\section{Net advection $F_{C}^{H A}$}

Similar to advection in the UEB and UWB, net horizontal advection of $\mathrm{CO}_{2}\left(F_{C}^{H A}\right)$ in urban areas is rarely addressed in studies. Results from a number of field experiments in forests (Aubinet et al. 2010) show, that there is a large uncertainty in quantifying horizontal and vertical advection fluxes. Both terms are large, are coupled and seem not to cancel each other. To date, it is not known how relevant this is for the urban environment.

\section{REFERENCES}

Allen, L., Lindberg, F. \& Grimmond, C. (2010). Global to city scale model for anthropogenic heat flux. International Journal of Climatology, $31,1990-2005$.

Arnfield, A. (2003). Two decades of urban climate research: a review of turbulence, exchanges of energy and water, and the urban heat island. International Journal of Climatology, 23, 1 - 26.

Aston, A. (1977). Water-resources and consumption in Hong Kong. Urban Ecology 2, 327 - 351.

Aubinet, M., Feigenwinter, C., Heinesch, B., Bernhofer, C., Canepa, E., Lindroth, A., Montagnani, L., Rebmann, C., Sedlak, P. \& Van Gorsel, E. (2010). Direct advection measurements do not help to solve the night-time $\mathrm{CO}_{2}$ closure problem: evidence from three different forests. Agricultural and Forest Meteorology, 150, 655 - 664.

Aubinet, M., Vesala, T. \& Papale, D., eds (2012). Eddy Covariance - a Practical Guide to Measurement and Data Analysis. Springer Atmospheric Sciences.

Berne, A., Delrieu, G., Creutin, J. \& Obled, C. (2004). Temporal and spatial resolution of rainfall measurements required for urban hydrology, Journal of Hydrology, 299, 166 - 179.

Berthier, E., Andrieu, H. \& Creutin, J. (2004). The role of soil in the generation of urban runoff: development and evaluation of a 2D model. Journal of Hydrology, 299, 252 - 266.

Berthier, E., Dupont, S., Mestayer, P. \& Andrieu, H. (2006). Comparison of two evapotranspiration schemes on a sub-urban site, Journal of Hydrology, 328, 635 - 646.

Branger, F., Kermadi, S., Jacqueminet, C., Michel, K., Labbas, M., Krause, P., Kralisch, S. \& Braud, I. (2013). Assessment of the influence of land use data on the water balance components of a peri-urban catchment using a distributed modelling approach. Journal of Hydrology, $505,312-325$.

Brutsaert, W. (1982). Evaporation into the Atmosphere: Theory, History and Applications, Springer.

Burian, S. J., McPherson, T., Brown, M., Streit, G. \& Turin, H. (2002). Modeling the effects of air quality policy changes on water quality in urban areas. Environ. Model. Assess. 7, $179-190$.

Camuffo, D. \& Bernardi, A. (1982). An observational study of heat fluxes and their relationship with net radiation. Boundary-Layer Meteorology, 23, 359 - 368.

Christen, A. (2005). Atmospheric turbulence and surface energy exchange in urban environments, PhD thesis, University of Basel, Stratus. ISBN 3-85977-266.X.

Christen, A., Coops, N., Crawford, B., Kellett, R., Liss, K., Olchovski, I., Tooke, T., van der Laan, M. \& Voogt, J. (2011). Validation of modeled carbon-dioxide emissions from an urban neighborhood with direct eddy-covariance measurements, Atmospheric Environment, $45,6057-6069$.

Christen, A. \& Vogt, R. (2004). Energy and radiation balance of a central European city. International Journal of Climatology, 24,1395 - 1421.

Chrysoulakis, N., Lopes, M., San José, R., Grimmond, C.S.B., Jones, M.B., Magliulo, V., Klostermann, J.E.M., Synnefa, A., Mitraka, Z., Castro, E., González, A., Vogt, R., Vesala, T., Spano, D., Pigeon, G., Freer-Smith, P., Staszewski, T., Hodges, N., Mills, G., \& Cartalis, C. (2013). Sustainable urban metabolism as a link between bio-physical sciences and urban planning: the BRIDGE project. Landscape and Urban Planning, 112, 100 - 117.

Clark-Thorne, S. \& Yapp, C. (2003). Stable carbon isotope constraints on mixing and mass balance of $\mathrm{CO}_{2}$ in an urban atmosphere: Dallas metropolitan area, Texas, USA, Applied Geochemistry, 18, 75 - 95.

Coutts, A., Beringer, J. \& Tapper, N. (2007). Characteristics influencing the variability of urban $\mathrm{CO}_{2}$ fluxes in Melbourne, Australia, Atmospheric Environment, 41, 51 - 62.

Crawford, B., Grimmond, C. \& Christen, A. (2011). Five years of carbon dioxide fluxes measurements in a highly vegetated suburban area. Atmospheric Environment 45, 896 - 905.

Denman, K., Brasseur, G., Chidthaisong, A., Ciais, P., Cox, P., Dickinson, R., Hauglustaine, D., Heinze, C., Holland, E., Jacob, D., Lohmann, U., Ramachandran, S., da Silva Dias, P., Wofsy, S. \& Zhang, X. (2007). Couplings Between Changes in the Climate System and Biogeochemistry. - In: Climate Change 2007: The Physical Science Basis. Contribution of Working Group I to the Fourth Assessment Report of the Intergovernmental Panel on Climate Change, Cambridge University Press, Cambridge, United Kingdom and New York, NY, USA. 
Lietzke B, R Vogt, DT Young, CSB Grimmond-2015: Physical fluxes in urban environment (Chapter 4). Understanding Urban Metabolism [ed N Chrysoulakis, E Castro, E Moors, Routledge, 29-44, http://www.routledge.com/books/details/9780415835114/

Ellefsen, R. (1990/91). Mapping and measuring buildings in the urban canopy boundary layer in ten US cities, Energy and Buildings, 15 $16,1025-1049$.

Feigenwinter, C., Vogt, R. \& Christen, A. (2012). Eddy covariance measurements over urban areas, in M. Aubinet, T. Vesala \& D. Papale, eds, Eddy Covariance - A Practical Guide to Measurement and Data Analysis, Springer Atmospheric Sciences, p. 430.

Foken, T., ed. (2008). Micrometeorology. Springer-Verlag Berlin Heidelberg.

Goldbach, A. \& Kuttler, W. (2013). Quantification of turbulent heat fluxes for adaptation strategies within urban planning. International Journal of Climatology, 33, 143 - 159.

Grimmond, C. (1992). The suburban energy balance: methodological considerations and results for a mid-latitude west coast city under winter and spring conditions. International Journal of Climatology, 12, 481 - 497.

Grimmond, C. (2006). Progress in measuring and observing the urban atmosphere. Theor. Appl. Climatol., 84, 3 - 22.

Grimmond, C., King, T., Cropley, F., Nowak, D. \& Souch, C. (2002). Local-scale fluxes of carbon dioxide in urban environments: methodological challenges and results from Chicago. Environmental Pollution, 116, 243 - 254.

Grimmond, C. \& Oke, T. (1986). Urban water-balance 2: Results from a suburb of Vancouver, British-Columbia. Water Resources Research, $22,1404-1412$.

Grimmond, C. \& Oke, T. (1991). An evapotranspiration-interception model for urban areas, Water Resources Research, 27,1739 - 1755.

Grimmond, C. \& Oke, T. (1995). Comparison of heat fluxes from summertime observations in the suburbs of four North American cities. Journal of Applied Meteorology, 34, 873 - 889.

Grimmond, C. \& Oke, T. (1999). Aerodynamic properties of urban areas derived from analysis of surface form. Journal of applied meteorology, $38,1262-1292$.

Grimmond, C., Oke, T. \& Steyn, D. (1986). Urban water-balance 1. a model for daily totals. Water Resources Research, 22,1397 - 1403.

Hathway, E. \& Sharples, S. (2012). The interaction of rivers and urban form in mitigating the urban heat island effect: A UK case study. Building and Environment, 58, 14 - 22.

Helfter, C., Famulari, D., Philipps, G., Barlow, J., Wood, C., Grimmond, C. \& Nemitz, E. (2011). Controls of carbon dioxide concentrations and fluxes above central London. Atmospheric Chemistry and Physics, 11, 1913 - 1928.

Hollis, G. E. \& Ovenden, J. (1988). The quantity of stormwater runoff from 10 stretches of road, a car park and 8 roofs in Hertfordshire, England during 1983. Hydrol. Process., 2, $227-243$.

Iamarino, M., Beevers, S. \& Grimmond, C. (2012). High-resolution (space, time) anthropogenic heat emissions: London 1970-2025. International Journal of Climatology, 32, 1754 - 1767.

Inkiläinen, E., McHale, M., Blank, G., James, A. \& Nikinmaa, E. (2013). The role of the residential forest in regulating throughfall: A case study in Raleigh, North Carolina, USA. Landscape and Urban Planning, 119, 91 - 103.

Järvi, L., Mammarella, I., Eugster, W., Ibrom, A., Siivola, E., Dellwik, E., Keronen, P., Burba, G. \& Vesala, T. (2009). Comparison of net CO 2 fluxes measured with open- and closed-path infrared gas analyzers in an urban complex environment. Boreal Environment Research, 14, 499 $-514$.

Järvi, L., Nordbo, A., Junninen, H., Riikonen, A., Moilanen, J., Nikinmaa, E. \& Vesala, T. (2012). Seasonal and annual variation of carbon dioxide surface fluxes in Helsinki, Finland, in 2006 - 2010. Atmospheric Chemistry and Physics Discussions, 12,8355 - 8396.

Järvi, L., Grimmond, C., Taka, M., Setälä, H., Nordbo, A. \& Strachan, I. (2014). Development of the Surface Urban Energy and Water balance Scheme (SUEWS) for cold climate cities. [In review] Geoscientific Model Development, MS No.: gmd-2013-163

Jia, Y., Ni, G., Kawahara, Y. \& Suetsugi, T. (2001). Development of WEP model and its application to an urban watershed. Hydrol. Process., $15,2175-2194$.

Kordowski, K. \& Kuttler, W. (2010). Carbon dioxide fluxes over an urban park area. Atmospheric Environment, 44, 2722 - 2730.

Kotthaus, S. \& Grimmond, C. (2012). Identification of micro-scale anthropogenic $\mathrm{CO}_{2}$, heat and moisture sources - processing eddy covariance fluxes for a dense urban environment. Atmospheric Environment, 57, 301 - 316.

Kotthaus, S. \& Grimmond, C.S.B. (2013a). Energy exchange in a dense urban environment - Part I: Temporal variability of long-term observations in central London. Urban Climate In Press, Corrected Proof, doi:10.1016/j.uclim.2013.10.002.

Kotthaus, S. \& Grimmond, C.S.B. (2013b).Energy exchange in a dense urban environment - Part II: Impact of spatial heterogeneity of the surface. Urban Climate In Press, Corrected Proof, doi: 10.1016/j.uclim.2013.10.001.

Lemonsu, A., Masson, V. \& Berthier, E. (2007). Improvement of the hydrological component of an urban soil-vegetation-atmosphere-transfer model. Hydrol. Process., 21, 2100 - 2111.

Lemonsu, A. \& Masson, V. (2002). Simulation of a Summer Urban Breeze Over Paris. Boundary Layer Meteorology, 104,463 - 490.

Lietzke, B. \& Vogt, R. (2013). Variability of $\mathrm{CO}_{2}$ concentrations and fluxes in and above an urban street canyon. Atmospheric Environment, $74,60-72$.

Lietzke, B., Vogt, R., Feigenwinter, C. \& Parlow, E. (2014, in review). On the variability of carbon-dioxide flux and its controlling factors in a heterogeneous urban environment. International Journal of Climatology .

Lindberg, F., Grimmond, C., Yogeswaran, N., Kotthaus, S. \& Allen, L. (2013). Impact of city changes and weather on anthropogenic heat flux in Europe 1995-2015. Urban Climate, 4, 1 - 15.

Loridan, T. \& Grimmond, C. S. B. (2012). Characterization of energy flux partitioning in urban environments: Links with surface seasonal properties. Journal of Applied Meteorology and Climatology, 51, 219 - 241.

Loridan, T., Grimmond, C. S. B., Offerle, B. D., Young, D. T., Smith, T. E. L., Jarvi, L. \& Lindberg, F. (2011). Local-scale urban meteorological parameterization scheme (lumps): longwave radiation parameterization and seasonality related developments. Journal of Applied Meteorology and Climatology, 50, 185-202.

Loridan, T., Lindberg, F., Jorba, O., Kotthaus, S., Grossman-Clarke, S. \& Grimmond, C. S. B. (2013). High resolution simulation of the variability of surface energy balance fluxes across central London with urban zones for energy partitioning. Boundary-Layer Meteorology, $147,493-523$.

Mitchell, V., Mein, R. \& McMahon, T. (2001). Modelling the urban water cycle. Environ. Modell. Softw.,16, 615 - 629.

Moriwaki, R. \& Kanda, M. (2004). Seasonal and diurnal fluxes of radiation, heat, water vapor, and carbon dioxide over a suburban area. Journal of Applied Meteorology, 43, 1700 - 1710.

Morris, B., Rueedi, J., Cronin, A., Diaper, C. \& DeSilva, D. (2007), Using linked process models to improve urban groundwater management: An example from Doncaster England, Water Environ. J. 21, 229-240.

Nouri, H., Beecham, S., Kazemi, F. \& Hassanli, A. M. (2012). A review of ET measurement techniques for estimating the water requirements of urban landscape vegetation. Urban Water Journal, 10, 247 - 259.

Offerle, B., Grimmond, C. S. B. \& Fortuniak, K. (2005). Heat storage and anthropogenic heat flux in relation to the energy balance of a Central European city centre. International Journal of Climatology, 25, 1405 - 1419.

Oke, T. (1979). Advectively-assisted evapotranspiration from irrigated urban vegetation. Boundary-Layer Meteorology, 17, 167 - 173.

Oke, T. (2006). Towards better scientific communication in urban climate. Theoretical and Applied Climatology, 84, 179 - 190. 
Lietzke B, R Vogt, DT Young, CSB Grimmond-2015: Physical fluxes in urban environment (Chapter 4). Understanding Urban Metabolism [ed N Chrysoulakis, E Castro, E Moors, Routledge, 29-44, http://www.routledge.com/books/details/9780415835114/

Oke, T., Kalanda, B. \& Steyn, D. (1981). Parameterization of heat storage in urban areas. Urban Ecology, 5, 45 - 54.

Oke, T. R. (1987). Boundary layer climates. Routledge, London.

Pataki, D., Bowling, D. \& Ehleringer, J. (2003). Seasonal cycle of carbon dioxide and its isotopic composition in an urban atmosphere: Anthropogenic and biogenic effects. Journal of Geophysical Research,108(D23), 4735 - 4742.

Pigeon, G., Legain, D., Durand, P. \& Masson, V. (2007a). Anthropogenic heat release in an old European agglomeration (Toulouse, France). International Journal of Climatology, 27, 1969 - 1981.

Pigeon, G., Lemonsu, A., Grimmond, C., Durand, P., Thouron, O. \& Masson, V. (2007b). Divergence of turbulent fluxes in the surface layer: case of a coastal city. Boundary-Layer Meteorology, 124, 269 - 290.

Piringer, M., Grimmond, C., Joffre, S., Mestayer, P., Middleton, D., Rotach, M., Baklanov, A., De Ridder, K., Ferreira, J., Guilloteau, E., Karppinen, A., Martilli, A., Masson, V. \& Tombrou, M. (2002). Investigating the surface energy balance in urban areas - recent advances and future needs. Water, Air and Soil Pollution: Focus, 2, 1 - 16.

Ragab, R., Bromley, J., Rosier, P., Cooper, J. \& Gash, J. (2003a). Experimental study of water fluxes in a residential area: 1. rainfall, roof runoff and evaporation: the effect of slope and aspect. Hydrol. Process., 17, 2409 - 2422.

Ragab, R., Rosier, P., Dixon, A., Bromley, J. \& Cooper, J. (2003b). Experimental study of water fluxes in a residential area: 2. road infiltration, runoff and evaporation. Hydrol. Process., 17, 2423 - 2437.

Ramamurthy, P. \& Pardyjak, E. (2011). Toward understanding the behavior of carbon dioxide and surface energy fluxes in the urbanized semiarid Salt Lake Valley, Utah, USA. Atmospheric Environment, 45, 73 - 84.

Raupach, M., Antonia, R. \& Rajagopalan, S. (1991). Roughwall turbulent boundary layers. Appl. Mechanics Reviews, 44,1 - 25.

Roberts, S., Oke, T., Grimmond, C. \& Voogt, J. (2006). Comparison of four methods to estimate urban heat storage. Journal of Applied Meteorology, 45, 1766 - 1781.

Rotach, M. (2001). Simulation of urban-scale dispersion using a lagrangian stochastic dispersion model. Boundary-Layer Meteorology, 99 , 379 410.

Rotach, M., Vogt, R., Bernhofer, C., Batchvarova, E., Christen, A., Clappier, A., Feddersen, B., Gryning, S.-E., Martucci, G., Mayer, H., Mitev, V., Oke, T., Parlow, E., Richner, H., Roth, M., Roulet, Y., Ruffieux, D., Salmond, J., Schatzmann, M. \& Voogt, J. (2005). BUBBLE - an urban boundary layer meteorology project. Theoretical and Applied Climatology, 81, 149 - 156.

Roth, M. \& Oke, T. (1994). Comparison of modelled and measured heat storage in suburban terrain. Beitr. Phys. Atmos,. 67,149 - 156.

Roth, M. \& Oke, T. (1995). Relative efficiencies of turbulent transfer of heat, mass and momentum over a patchy urban surface. Journal of Atmospheric Sciences, 52, 1864 - 1874.

Sailor, D. (2010). A review of methods for estimating anthropogenic heat and moisture emissions in the urban environment. International Journal of Climatology, 31, 189 - 199.

Schmid, H. P. \& Rotach, M. W. (1997). Grenzschichtmeteorologie, ETH, Zurich.

Semadeni-Davies, A. F. \& Bengtsson, L. (1999). The water balance of a sub-Arctic town. Hydrol. Process., 13,1871 - 1885.

Spronken-Smith, R. A., Oke, T. \& Lowry, W. (2000). Advection and the surface energy balance across an irrigated urban park. International Journal of Climatology, 20, 1033 - 1047.

Spronken-Smith, R., Kossmann, M. \& Zawar-Reza, P. (2006). Where does all the energy go? Surface energy partitioning in suburban Christhurch under stable wintertime conditions. Theoretical and Applied Climatology, 84, 137 - 149.

Steeneveld, G. J., Koopmans, S., Heusinkveld, B. G. \& Theeuwes, N. E. (2014). Refreshing the role of open water surfaces on mitigating the maximum urban heat island effect. Landscape and Urban Planning, 121, 92 - 96.

Stephenson D (1994) Comparison of the water-balance for an undeveloped and a suburban catchment. Hydrol. Sci. J.-J. Sci. Hydrol,. 39,295 307.

Stewart, I. D. \& Oke, T. R. (2012). Local climate zones for urban temperature studies. Bulletin of the American Meteorological Society, 93,1879 $-1900$.

Trusilova, K. \& Churkina, G. (2008). The response of the terrestrial biosphere to urbanization: land cover conversion, climate, and urban pollution. Biogeosciences, 5, 1505 - 1515.

Vieux B, Bedient P (2004) Assessing urban hydrologic prediction accuracy through event reconstruction. Journal of Hydrology, 299,217 - 236.

Vogt, R., Christen, A., Rotach, M. W., Roth, M. \& Satyanarayana, A. N. V. (2006). Temporal dynamics of $\mathrm{CO}_{2}$ fluxes and profiles over a Central European city. Theoretical and Applied Climatology, 84, 117 - 126.

Wang, J., Endreny, A. \& Nowak, D. J. (2008). Mechanistic simulation of tree effects in an urban water balance model. Journal of the American Water Resources Association, 44, 75 - 85.

Ward, H., Evans, J. \& Grimmond, C. (2013). Multi-season eddy covariance observations of energy, water and carbon fluxes over a suburban area in Swindon, UK. Atmospheric Chemistry and Physics, 13, 4645 - 4666.

Xiao, Q., McPherson, E., Simpson, J. \& Ustin, S. (2007). Hydrologic processes at the urban residential scale. Hydrol. Process., 21,2174 - 2188. 